\title{
Arab EFL Learners' Identification of English Sentence Patterns
}

\author{
Aisha M. Alhussain ${ }^{1}$ \\ ${ }^{1}$ Princess Nourah bint Abdulrahman University, KSA \\ Correspondence: Aisha M. Alhussain, Princes Nourah bint Abdulrahman University, Riyadh, KSA. E-mail: \\ amalhusian@pnu.edu.sa
}

Received: November 17, 2017 Accepted: January 31, 2018 Online Published: February 4, 2018

doi:10.5539/ijel.v8n3p158

URL: http://doi.org/10.5539/ijel.v8n3p158

\begin{abstract}
The article investigated if a significant relationship existed between Arab EFL learners' and the English sentence pattern identified. The participants were 64 third-year college students studying in the Department of Linguistics at Princess Nourah University, Saudi Arabia. They were assigned 28 literary texts and asked to derive examples for each of the nine sentence patterns listed in Stageberg (1981). An ANOVA test at alpha level $P<0.05$ and a post hoc test were used to analyze data. The findings of the study showed a highly significant result at $p<0.05$ between participants' performance and the pattern identified. Seven levels of difficulty were identified, where Pattern 1 was the easiest and Pattern 8 was the most difficult. The main components of each English sentence pattern were also investigated to find possible sources of difficulty, such as the use of the copula; transitive, intransitive, and ditransitive verbs; dative case; and double object structure. The denoting of referents, dative case, and double object structures were found to be the main sources of difficulty.
\end{abstract}

Keywords: EFL Arab learners, sentence pattern identification, EFL learners' source of errors, dative case, and double object structure

\section{Introduction}

\subsection{Arab EFL Learners'Identification of English Sentence Patterns}

It is widely believed that most languages have similar sentence structures, but differ in their morphological structures (Haspelmath, 1993). Morphologically, languages are classified as either analytic or synthetic. An analytic language is one with little inflection whereas a synthetic one is inflectional. English is considered an analytic language while Arabic is synthetic (Al-Shujairi, 2015). Accordingly, many differences exist between the two languages.

An important aspect of such differences can be found in the two languages' sentence patterns. In English, words are arranged in patterns to give the correct meaning of the sentence. English sentence patterns are taught to EFL/ESL learners to improve their writing and speaking skills, and they are considered an important tool that students need to master for their reading and writing skills (Hostmeyer, 2016; Su, 2001). This knowledge is also crucial for precise translation production as well. Thus, not surprisingly, many books offer explanations and examples of how to form sentences in English following the main English sentence patterns to help develop flexibility and ease in written and reading work (Landon, 2013).

Many studies have compared Arabic and English sentence patterns (e.g., Alduais, 2012; Al-Shujairi, 2015; Breedlove, 2017) to raise awareness about how to construct sentences into common patterns to avoid confusion and add clarity to sentences. Breedlove's (2017) book helps English and Arabic students understand the differences between the two languages with respect to verb time, tense, aspect, mood, and transitive/intransitive structure. Alduais (2012) contrasted the simple sentence structure of English and Arabic to show that Arabic has four types of simple sentences (i.e., nominal, verbal, equational, and non-verbal) compared to English's single type (i.e., nominal). Al-Shujairi (2015) investigated transitivity and intransitivity in English and Arabic, noting similarities and differences. Both languages have transitive and intransitive verbs, but Arabic uses inflection to change an intransitive verb to a transitive one.

Yet few studies have focused on how well students identify English sentence patterns. Saif Al-Deen (2009) verified the hypothesis that "there is statistical significant differences among the Iraqi college students' ability in identifying sentence patterns" (p. 11). She carried out an 18-item achievement test with 30 third-year college students in an English department in Iraq using the sentence patterns Stageberg (1981) identified. An analysis of 
the data showed that students could identify P1, P2, P3, and P4 well but not P5, P6, P7, P8, or P9. The study identified probable factors causing this low performance, such as pattern complexity and L1 interference, but these factors were not verified. Saif Al-Deen suggested the need for further research to determine the possible influence that Arabic sentence patterns might have on learners' ability to identify and use English sentence patterns correctly. A review of the literature found no further studies on EFL learners' ability to identify sentence patterns. Such studies are used as an assessment tool that is crucial to the education process where learners' needs are addressed, which may in turn result in having effective teaching plans. Three types of assessments exist: initial, summative, and formative. Initial assessments are used to identify learning and support needs before the start of the learning process to produce successful teaching plans. Summative assessment measures students' achievement at the end of semester to ensure that they have met the required standard to earn certification. Formative assessment provides a frequent and interactive assessment to measure students' progress and understanding to identify needs and adjust teaching appropriately (Bloom, Hastings, \& Madaus, 1971). Thus, a measure that assesses learners' ability to identify English sentence patterns correctly would be useful in any of these processes (i.e., identify weaknesses for teaching, monitor progress, and assess learners' performance against specified targets).

As an EFL teacher for 28 years who has been teaching English sentence patterns for 15 years as part of a linguistics course, I found that the results of Saif Al-Deen's (2009) study to, at first glance, not correspond to my students' performance. I became interested in further investigating how Arab EFL learners identify English sentence patterns by testing the null hypothesis that "no statistically significant relationship exists between students' performance and the pattern they identified." To this end, the current study uses a different assessment method and a bigger number of participants. It also fills the gap by investigating the probable reasons behind students' failure or low performance in identifying any of the tested sentence patterns if they occur by analyzing the basic linguistic elements in each sentence pattern and by determining if Arabic sentence patterns have any influence on students' performance.

\section{Statement of the Study Problem}

This study aims to assess Arab ELF learners' ability to identify English sentence patterns by testing the null hypothesis that "no statistically significant relationship exists between the students" performance and the pattern they identified" and examining the possible influence of Arabic sentence patterns on students' ability or inability to identify them. Different linguistic elements will be investigated to shed light on the sources of difficulty.

Most errors in writing and reading are attributed to a lack of awareness of how to construct a proper English sentence pattern (Hostmeyer, 2016; Su, 2001). In this paper, I will conduct a formative assessment with 64 Arab EFL students to investigate their ability to identify English sentence patterns in literary texts. This study may contribute to a growing understanding of EFL learners' sources of errors, which will help teachers adopt more effective instruction in English sentence patterns.

\section{Aims of the Study}

This paper has a twofold aim: The first is to test the null hypothesis that "no statistically significant relationship exists between the students' performance and the English pattern they identified." The second is to find sources of difficulty facing Arab EFL learners when they identify English sentence patterns and then determine if they are related to the negative influence of $\mathrm{L} 1$.

\section{Methodology}

\subsection{Assessment Tool}

The present study used a different assessment tool than was used in Saif Al-Deen's (2009) study. Students were asked to identify English sentence patterns by deriving examples from novels and short stories rather than giving them sentences and asking them to state the patterns. In other words, language and literature were incorporated. Many studies have demonstrated the popularity of using literature as a tool to teach language skills and language areas such as grammar (Collie \& Salter, 1987; Hismanoglu, 2005; Sage, 1987). These studies have suggested that literary texts can be a rich source for appropriate pedagogically designed materials for use by language teachers. Abdulmughni (2016) stated that using literature is the best way to speed the language learning process and facilitate students' enjoyment and motivation. This type of assessment can give a measure for understanding where students are put at ease while enjoying reading different novels and stories.

\subsection{Participants}

The participants of the study were 64 third-year college students studying at the Department of Linguistics at Princess Nourah University, Saudi Arabia. They have almost the same English background and study the same 
English courses. As part of their program, these students complete a course in linguistics in which they study English sentence patterns among other aspects of the language. The textbook used is An Introductory English Grammar (4th ed.) by Norman C. Stageberg.

\subsection{Procedure}

As part of their course in linguistics, the participants received explanation and practice on the basic English sentence patterns. Most grammar books (e.g., Stageberg, 1981) agree that there are nine main English sentence patterns (see Table 1).

Table 1. English sentence patterns

\begin{tabular}{|c|c|c|c|c|c|}
\hline No. & \multicolumn{4}{|c|}{ Pattern Symbols } & \multirow{2}{*}{$\begin{array}{l}\text { Examples } \\
\text { He is lovely }\end{array}$} \\
\hline P.1 & N1 & $\mathrm{Be}$ & $\mathrm{AJ}$ & & \\
\hline P.2 & N1 & $\mathrm{Be}$ & AV & & My friends are at the concert \\
\hline P.3 & N1 & $\mathrm{Be}$ & N1 & & They are players \\
\hline P.4 & N1 & LV & $\mathrm{AJ}$ & & The cake on the table looks delicious \\
\hline P.5 & N1 & LV & $\mathrm{N} 1$ & & Joan became a geologist \\
\hline P.6 & N1 & $\operatorname{InV}$ & & & The baby smiled beautifully \\
\hline P.7 & N1 & $\operatorname{TrV}$ & $\mathrm{N} 2$ & & The archer shot an arrow into the target \\
\hline P.8 & N1 & $\operatorname{TrV}$ & $\mathrm{N} 2$ & $\mathrm{~N} 3$ & The supervisor mailed the applicant a description of the job \\
\hline P.9 & $\mathrm{N} 1$ & $\operatorname{TrV}$ & $\mathrm{N} 2$ & $\mathrm{~N} 2$ & Most people consider Jacobsen a loyal friend \\
\hline
\end{tabular}

To measure the participants' performance and understanding of these patterns, a formative assessment was conducted. Students were assigned 28 works of literature (see Appendix A) and asked to choose nine of them from which to derive four examples of each English sentence pattern. Participants were directed from the beginning to pay attention to documentation, so the source of the examples could be easily validated. For each example, they gave the title of the work, the author, the page, and line number. Each student was asked to provide 36 examples from 9 works of literature. The total number of correct sentences derived from 28 literary sources was 1608 sentences out of 2304 (see Table 2)

Table 2. Summary

\begin{tabular}{lllll}
\hline Groups & Count & Sum & Average & Variance \\
\hline P1 & 64 & 232 & 3.625 & 0.873016 \\
P2 & 64 & 164 & 2.5625 & 2.72619 \\
P3 & 64 & 200 & 3.125 & 2.015873 \\
P4 & 64 & 182 & 2.84375 & 2.260913 \\
P5 & 64 & 168 & 2.625 & 2.777778 \\
P6 & 64 & 218 & 3.40625 & 1.356151 \\
P7 & 64 & 188 & 2.9375 & 2.281746 \\
P8 & 64 & 92 & 1.4375 & 2.980159 \\
P9 & 64 & 164 & 2.5625 & 3.234127 \\
\hline
\end{tabular}

An ANOVA single factor test was conducted to detect any statistically significant relationship between the students' performance and the English sentence patterns they identified. An alpha of $\mathrm{P}<0.05$ was used as the cutoff for significance. A post hoc test was implemented to define levels of difficulty.

\section{Results and Discussion}

The analysis of the data showed that the relationship between participants' performance and the English sentence patterns they identified was highly significant, $\mathrm{F}(8,567)=11.14, P=0.00$. The data are summarized in Table 3 .

Table 3. ANOVA: single factor

\begin{tabular}{lllllll}
\hline Source of Variation & SS & df & MS & F & $\boldsymbol{P}$-value & F crit \\
\hline Between Groups & 203.125 & 8 & 25.39062 & 11.14387 & 0.00000000000001 & 1.95472 \\
Within Groups & 1291.875 & 567 & 2.278439 & & & \\
Total & 1495 & 575 & & & & \\
\hline
\end{tabular}

The $P$ value $(0.00)$ is smaller than 0.05 , so we reject the null hypothesis that "no statistically significant 
relationship exists between the students' performance and the English sentence pattern they identified." We further accept the alternative hypothesis that a statistically significant relationship exists between the participants' performance and the English sentence pattern they identified. The second step was to conduct a post hoc test to determine which group means differ. Thirty-six comparisons were made between groups. Table 4 summarizes the results.

Table 4. P values of the post hoc test

\begin{tabular}{llllllllll}
\hline & P1 & P2 & P3 & P4 & P5 & P6 & P7 & P8 & P9 \\
\hline P1 & $\#$ & .00 & .02 & .00 & .00 & .24 & .00 & .00 & .00 \\
P2 & .00 & $\#$ & .04 & .31 & .83 & .00 & .18 & .00 & 1.00 \\
P3 & .02 & .04 & $\#$ & .27 & .07 & .22 & .47 & .00 & .05 \\
P4 & .00 & .31 & .27 & $\#$ & .43 & .01 & .72 & .00 & .33 \\
P5 & .00 & .83 & .07 & .43 & $\#$ & .00 & .26 & .00 & .83 \\
P6 & .24 & .00 & .22 & .01 & .00 & $\#$ & .05 & .00 & .00 \\
P7 & .00 & .18 & .47 & .72 & .26 & .05 & $\#$ & .00 & .20 \\
P8 & .00 & .00 & .00 & .00 & .00 & .00 & .00 & .00 & .00 \\
P9 & .00 & 1.00 & .05 & .33 & .83 & .00 & .20 & .00 & $\#$ \\
\hline
\end{tabular}

After completing the comparisons, a Bonferroni correction test was applied to account for any increase in error rate due to the repeated tests; the result was a Bonferroni-corrected alpha of $P<001$. Pattern 1 was significantly different from Patterns 2, 4, 5, 7, 8, and 9. Pattern 2 differed significantly from Patterns 6, 1 , and 8 . Pattern 3 was significantly different only from Pattern 1. Pattern 4 was significantly different from Patterns 1 and 8. Pattern 5 differed significantly from Patterns 1, 6, and 8. Pattern 6 showed a significant difference from Patterns 2, 5, 8, and 9. Pattern 7 was significantly different from Patterns 1 and 8. Pattern 8 was significantly different from all patterns. Pattern 9 differed significantly from Patterns 1, 6, and 8. Figure 1 illustrates the relationship between the participants' performance and the pattern they identified.

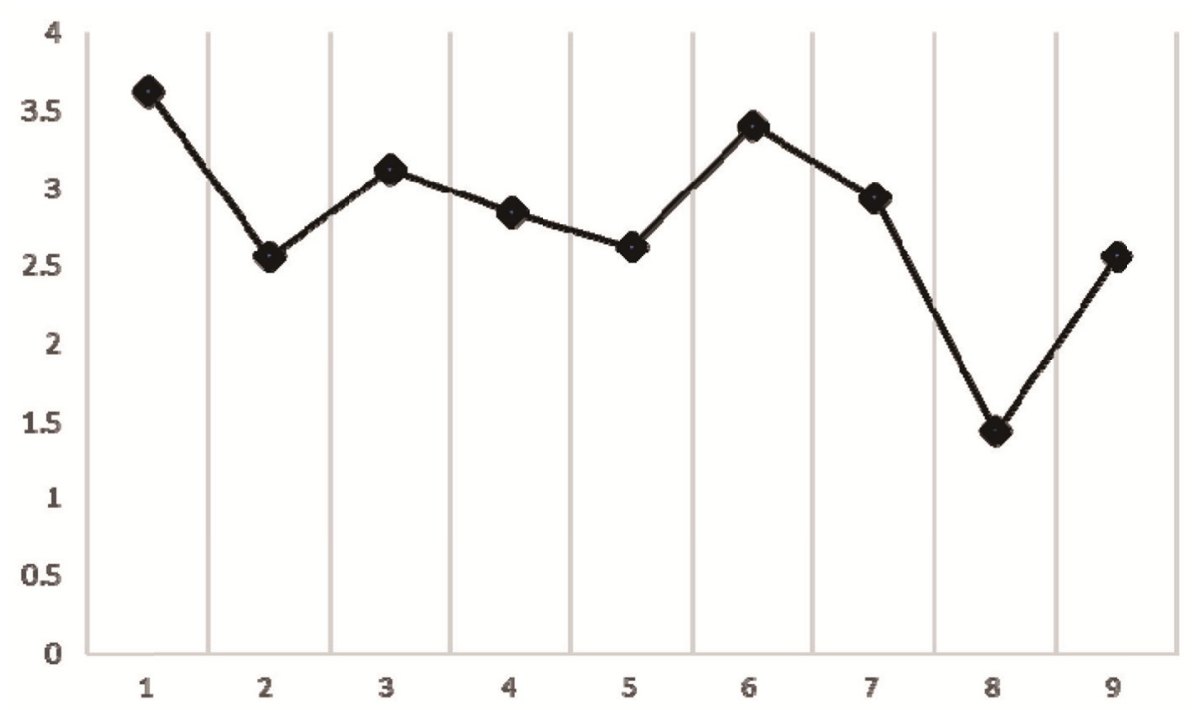

Figure 1. The relationship between participants' performance and the identified pattern

Figure 1 indicates that the participants performed very highly when they identified Pattern 1 and performed very low when they identified Pattern 8. Figure 2 demonstrates seven levels of difficulty when sentence patterns are identified. 


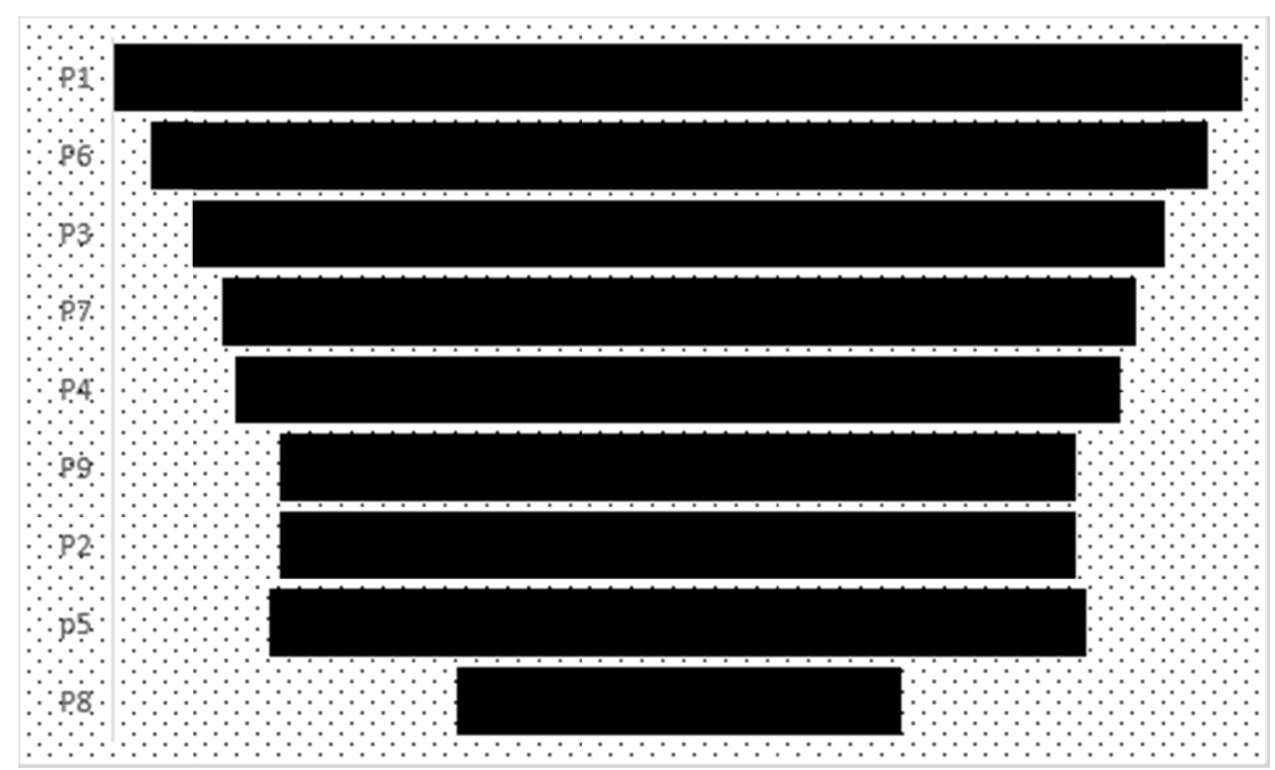

Figure 2. Levels of difficulty in identifying sentence patterns

In Figure 2, from the top to the bottom, Pattern 1 is the easiest one, followed by Patterns 6 (second level), 3 (third level), 7 and 4 (fourth level), 9 and 2 (fifth level), 5 (sixth level), and 8 (the seventh and hardest level).

To conclude, participants could identify all English sentence patterns in literary texts, but the extent of the identification varied from one pattern to another. Pattern 8 was found to be the most difficult one while Pattern 1 was the easiest. These results differ from those of Saif Al-Deen's (2009), which categorized the patterns in two groups-identified or not identified. The present study concluded that all patterns could be identified with variation, and it placed the patterns into levels ranging from the easiest pattern to the most difficult one. Another aspect of difference was found as Saif Al-Deen classified Patterns 1, 2, 3, and 4 into one easy category whereas the present study categorized them differently; for instance, Pattern 1 is in the first level, Pattern 2 in the fifth level, Pattern 3 in the second level, and Pattern 4 in the fourth level. A third difference is in the brief analysis of Patterns 5, 6, 7, 8, and 9 in Saif Al-Deen's results, where Pattern 6 was considered an unidentified pattern whereas it was included in the second level of easy identification in the current study. Patterns 7 and 9 were also considered differently from the present research. Participants in the current study more clearly delineated Pattern 8, finding it to be the most difficult pattern; however, in Saif Al-Deen's study, Patterns 5, 6, 7, 8, and 9 were considered equal in terms of difficulty level. The current study classified patterns statistically and more accurately, concluding that Pattern 8 was statistically the most difficult pattern.

The next step was to investigate the main component(s) of each English sentence pattern, whether identical to, different from, or absent from the Arabic language, to determine the possible sources of difficulty reflected in the participants' performance.

\subsection{Basic Sentence Patterns Related to Copulas: Verbs "to be" and Linking Verbs}

The term copula refers to verbs used to link the subject with a predicate. English is described as a copulative language because it has two copulas: the verb "to be," which has little independent meaning, and linking verbs (become, feel, etc.). Arabic is considered in several studies to be a non-copulative language because it does not have similar copulas; many EFL learners' errors are attributed to this difference (Tahir, 2009).

\section{A. "To be"}

Recent studies have reconsidered the classification of "to be" and suggested that this copula can be expressed explicitly or implicitly (Abu-Chacra, 2007; Badawi, Carter, \& Gully, 2014; Sarage, 2014; Soltan, 2011; Tahir, 2009). The copula in English is expressed explicitly by verbs like $i s$, was, etc., but it is expressed implicitly in Arabic through a linguistic phenomenon called "zero copula," where the subject and predicate are joined but not overmarked in present tense, but rather the past tense with the verb "kana." Patterns 1, 2, and 3 have the copula "to be." The participants' performance varied in these three patterns. Pattern $1(\mathrm{~N} \mathrm{Be} A j)$ was easily identified, followed by Pattern 3 (N1 Be N1). Most errors found in identifying Pattern 3 occurred in deciding on the identical referent to the first noun. Arabic students found the verb "to be" easy to identify if no other difficult 
elements coexisted. In Pattern 2 (N1 Be Av), the presence of an adverb made it difficult for participants to identify the pattern, although Arabic language has different types of adverbs just like in English. This finding corresponds to studies showing that EFL learners have difficulty mastering English adverbs, although they are present in their mother tongue (Leedham \& Cai, 2013; Lei, 2006; Narita \& Sugiura, 2006).

\section{B. Linking verbs}

Arabic language has linking verbs, but a fewer number than English. When we look closely into the errors made by the participants when identifying Pattern 4 (N1 LV Aj), we find them related to some linking verbs that do not exist in Arabic; however, participants could identify most English linking verbs that do not exist in Arabic. Participants who could not recognize Pattern 5 (N1 LV N1) faced the problem of finding the referent of the two nouns. Although copula use in English and Arabic is not identical, students could identify it in Patterns 1, 2, 3, 4, and 5 but faced other obstacles. These results minimize the extensive reference to L1 in EFL learners' error sources and draw attention to other possible difficulty sources.

\subsection{Basic Sentence Patterns Related to Transitive and Intransitive Verbs}

Many studies have been conducted to compare transitivity and intransitivity in English and Arabic (e.g., Al-Shujairi, 2015). Similarities and differences have been noted. English and Arabic were found to be similar in having transitive verbs and intransitive verbs that can be transitive or intransitive according to context. Both languages have ditransitive verbs that can take two objects. On the other hand, English and Arabic are different in two aspects. In Arabic, inflections play a role in changing intransitive verbs into transitive ones; for example, the Arabic intransitive verb "jalasa" can be changed into transitive by fronting "hamzah" (أ) to become "ajlasa" or by doubling the middle letter. Another difference is that some Arabic verbs can take three objects-for example, "Áclamtw clay mwhamad mwsäfirāa (I told Ali that Mohammed will travel)"-unlike English, which has only two objects. Thus, the assumption that transitive and intransitive verbs might not exist in Arabic is excluded (Saif Al-Deen, 2009).

Students could identify Pattern 6 (N1 Intr) easily in this study. Pattern 7 (N1 Trv N2), which contains a transitive verb, was identified with a greater level of difficulty due to confusion in recognizing if the second noun has the same referent as the first one. It can be concluded that students were quite readily able to identify patterns with transitive and intransitive verbs. The level of difficulty increased, however, as students dealt with Pattern 9 (N1 Trv N2 N2) and reached its peak with Pattern 8 (N1 TrvN2 N3). The shared feature between Pattern 8 and Pattern 9 is that both have a ditransitive verb. Ditransitive verbs that require two objects are complex and confusing for EFL/ESL learners (Hang, 2007; Nagano, 2015; Wang, 2012). This conclusion will lead us to investigate another possible source: dative case and double object structures.

\subsection{Dative Case and Double Object Structures}

A dative case refers to a noun or a pronoun when it is used as an indirect object followed by a direct one. For example, in "he gave his daughter a camera for Christmas," "his daughter" is a noun in the dative case because it is used as an indirect object and followed by the noun "camera" as a direct one. The sentence structure is called a double object structure because it consists of two objects for one transitive verb. The dative and the double object structure are considered a critical and sensitive case in language processing even for native English speakers (Hovana \& Levin, 2008; Snedeker, 2015).

Al-Tamari (1999) investigated dative and double object structures in English and Arabic to shed light on the challenging problems related to them and how previous approaches failed to analyze them. He proposed a minimalist approach introduced by Chomsky (1993) as a solution to analyze dative and double object structures in both languages. He believed that this approach is efficient in accounting for asymmetries in double object structures. Arab learners faced difficulty with ditransitive verb and double object structure, even though these structures exist in Arabic.

To conclude, this study found other sources of difficulty facing Arab learners in identifying some English sentence patterns, such as denoting referents and datives and double object structure that exist in L1 rather than the excessive reference to the mother tongue's negative influence. The dative and double object structures were found to be the main source of difficulty facing participating students in identifying Patterns 8 and 9 .

\section{Conclusion}

This paper sought to achieve different goals. It was designed to investigate if a significant relationship exists between Arab EFL learners' performance in identifying English sentence patterns in literary texts and the pattern they identified. The results showed that participants could identify all sentence patterns and that the relationship between their performance and the pattern they identified was significant at $p<0.05$. Seven levels of 
performance were found, starting from level one-occupied by the easiest Pattern 1 -and continuing up the scale in order to Patterns 6;3;4 and 7;2 and 9;5; and 8. The second goal was to find the possible causes of this variation in performance and examine some of the patterns' components that might be a source of difficulty. Referents denoting, dative and double structures were found to be a source of difficulty. Previously, most EFL/ESL learners' errors in the target language have been extensively attributed to L1, but this study showed the two cases where the element was present in L1 but still not identified by students and vice versa. More focus on these components is recommended when teaching English sentence patterns to Arab EFL learners. Further studies should compare native and non-native performance to determine if any differences occur. Additional studies could also apply a method of teaching focusing on referents, datives, and the double object structure.

\section{References}

Abdulmughni, S. (2016). Teaching skills through Literature. International Journal of Applied Linguistics, 5(2), $10-16$.

Abu-Chacra, F. (2007). Arabic :An Essential Grammar. New York: Routledge.

Alduais, A. (2012). Simple sentence structure of standard Arabic language and standard english language : a contrastive study. International Journal of Linguistics, 4(4), 38-52. https://doi.org/10.5296/ijl.v4i4.2621

Al-Shujairi, Y. (2015). Transitivity and Intransitivity in English and Arabic: A comparative study. International Journal of Linguistics, 7(6), 500-524. https://doi.org/10.5296/ijl.v7i6.8744

Al-Tamari, E. (1999). Dative and double object structures in standard Arabic (SA) and English: A minimalist approach. Kansas Working Papers in Linguistics, 24, 41-57. https://doi.org/10.17161/KWPL.1808.353

Badawi, E., Carter, M., \& Gully, A. (2014). Modern Written Arabic: A comprehensive Grammar. New York: Routledge.

Bloom, B., Hastings, J., \& Madaus, G. (1971). Handbook on Formative Evaluation of Student Learning. New York: McGraw-Hill.

Breedlove, C. (2017). Arabic and English Sentence Patterns: a Comparative Study. Portland: Portland State University. https://doi.org/10.15760/pdxopen-11

Chomsky, N. (1993). A minimalist program for linguistic theory. In K. Hale \& S. Keyser (Eds.), The View from Building 20: Essays in Linguistics in Honor of Sylvain Bromberger (pp. 1-9). Cambridge: MIT Press.

Collie, J., \& Salter, S. (1987). Literature in the Language classroom:A resource Book of Ideas and Activities. Cambridge: Cambridge University Press.

Hang, T. (2007). Ditransitive Verbs in English and Vietnamese. Retrieved from http://hdl.handle.net/123456789/2081

Haspelmath, M. (1993). More on the Typology of Inchoative/Causative Verb Alternations. In B. Comrie, \& M. Polinsky. Causitives and Transitivity (pp. 87-120). New York: John Benjamins. https://doi.org/10.1075/slcs.23.05has

Hismanoglu, M. (2005). Teaching English Through Literature. Journal of Language and Linguistics Studies, $1(1), 53-66$.

Hostmeyer, P. (2016). Tools Students Need to be Skillful Writers: Building Better Sentences. Thousand Oaks: Corwin Press.

Hovava, M. R., \& Levin, B. (2008). The English dative alternation: The case for verb sensitivity. Journal of Linguistics, 44(1), 129-167. https://doi.org/10.1017/S0022226707004975

Landon, B. (2013). Building Great Sentences:How to Write the Kinds of Sentence You Love to Read. New York: Penguin Group.

Leedham, M., \& Cai, G. (2013). Besides...on the other hand :Using a corpus approach to explore the influence of teaching materials on Chines students' use of linking adverbials. Journal of Second Language Writing, 22(4), 374-389. https://doi.org/10.1016/j.jslw.2013.07.002

Lei, L. (2012). linking adverbials in academic writing on applied linguistics by Chineses doctoral students. Journal of English for Academic Purposes, 11(3), 267-275. https://doi.org/10.1016/j.jeap.2012.05.003

Nagano, T. (2015). Acquisition of English verb transitivity by native speakers of Japanese. Linguistics Approach to Bilingualism, 5(3), 322-355. https://doi.org/10.1075/lab.5.3.02nag 
Narita, M., \& Sugiura, M. (2006). The use of adverbial connectors in argumentative essays by Japanese EFL college students. English Corpus Studies, 13, 23-42.

Sage, H. (1987). Incorporating literature in ESL instruction.Language in education:Theory and practice. New Jersey: Prentice-Hall.

Saif Al-Deen, M. (2009). Investigation of the Students' Ability to Identify the Sentence Pattern. Journal of Tikrit University for the Humanities, 17(3), 9-26.

Sarage, J. (2014). The zero copula in Russian and Arabic sentences as Compared with English . International Journal on Studies in English Language and Literature, 2(11), 119-126.

Snedeker, J. (2015). Children's Sentence Processing. In L. Bavin, \& L. Naigles, The Handbook of Child Language (pp. 321-338). Cambridge: Cambridge University Press. https://doi.org/10.1017/CBO9781316095829.019

Soltan , U. (2011). On issues of Arabic syntax:an essay in syntactic argumentation. Brill's Annual of Afroasiatic Languages and Linguistics, 3, 236-280. https://doi.org/10.1163/187666311X562486

Stageberg, N. (1981). An introductory English grammar (4th ed.). New York: Rineheart and Winston.

$\mathrm{Su}$ I. R. (2001). Transfer of sentence processing strategies:A comparison of L2 learners of Chines and English. Applied Psycholinguistics, 22(1), 83-112. https://doi.org/10.1017/S0142716401001059

Tahir, I. (2009). Copula in standard English and its Counterpart in Standard Arabic. Al-Fatih Journal, 39, 1-9.

Wang, H. C. (2012). A study of Taiwanese EFL learners' Syntactic Transfer in Verb Transitivity. Theory and Practice in Language Studies, 2(10), 1993-2001. https://doi.org/10.4304/tpls.2.10.1993-2001

\section{Appendix A}

\section{Novels, Short Stories, Plays, and Poems}

1. Great Expectations by Charles Dickens

2. Jane Eyre by Charlotte Bronte

3. She Stoops to Conquer by Oliver Goldsmith

4. The Mayor of Casterbridge by Thomas Hardy

5. "The Lotos-Eaters" by Lord Tennyson

6. "Mariana" by Lord Tennyson

7. "The Scholar Gypsy" by Matthew Arnold

8. "Dover Beach" by Matthew Arnold

9. "The Cry of the Children" by Elizabeth Browning

10. The Rivals by Richard Sheridan

11. The Merchant of Venice by William Shakespeare

12. The Odd Women by George Gissing

13. To the Lighthouse by Virginia Woolf

14. "Split Cherry Tree" by Jesse Stuart

15. The Voyages of Doctor Dolittle by Hugh Lofting

16. "The Black Veil" by Charles Dickens

17. "Mother Hen and Robber Hawk" by Robert Gordon Anderson

18. "Homework" by Guy Hasson

19. Alice's Adventures in Wonderland by Lewis Carroll

20. Eclipse by Stephenie Meyer

21. Twilight by Stephenie Meyer

22. A Passage to India by E.M. Forster

23. Hamlet by Shakespeare 
24. The Time Machine by H.G. Wells

25. Second Chance Romance by Asrai Devin

26. Pride and Prejudice by Jane Austen

27. Emma by Jane Austen

28. "The Monkey's Paw" by W.W. Jacobs

\section{Copyrights}

Copyright for this article is retained by the author(s), with first publication rights granted to the journal.

This is an open-access article distributed under the terms and conditions of the Creative Commons Attribution license (http://creativecommons.org/licenses/by/4.0/). 